\title{
A Comparison between the Results of Open versus Closed Lateral Internal Sphincterotomy in the Surgical Management of Chronic Anal Fissure
}

\author{
Mahabub $M^{\mathrm{a}}$, Rahman $\mathbf{M}^{\mathrm{b}}$, Islam $\mathbf{T}^{\mathrm{c}}$, Sultana $\mathrm{S}^{\mathrm{d}}$
}

\begin{abstract}
Background: Lateral internal sphincterotomy is regarded as the gold standard surgical treatment for chronic anal fissure. Some authors reported that the closed technique had lower complication rates than that by the open technique, but others reported that both of the techniques had no meaningful differences in complications.

Methods: This was a comparative and cohort study carried out at Department of Colorectal Surgery, Combined Military Hospital (CMH) Dhaka, Bangladesh, from October 2013 to October 2017. Eighty three patients with chronic anal fissure not responding to medical treatment for at least three months were included in this study to compare the results of the open versus closed techniques of lateral internal sphincterotomy after four months follow up postoperatively.
\end{abstract}

Results: The mean age at presentation was $34.15 \pm 11.4$ years and the male to female ratio was 1.24:1. The results of open and closed tech-niques were compared regarding per-operative bleeding (35.71\% versus $12.19 \%)$, post-operative urinary retention (4.76\% versus $0 \%)$, symptom relief on first post-operative day (76.19\% versus $70.73 \%)$, significant $1^{\text {st }}$ post-operative day pain in the operated wound (33.33\% versus $\left.7.31 \%\right)$, temporary fecal soiling (2.38\% versus $0 \%)$, temporary flatus in-continence (7.14\% versus $0 \%)$, and fissure recurrence ( $0 \%$ ver-sus $14.63 \%)$ respectively. Temporary incontinence to fecal and flatus recovered by conservative management within two and four months of surgery respectively.

Conclusion: The closed technique of lateral internal sphincterotomy had lower post-operative complications, pain, bleeding, and incontinence compared to open technique, but increased risk of fissure recurrence.

Keywords: Chronic anal fissure (CAF), lateral internal sphincterotomy (LIS), open lateral internal sphincterotomy (OLS), closed lateral internal sphincterotomy (CLS).

(BIRDEM Med J 2018; 8(3): 235-239)

Author Information

a. $\quad$ Lt. Colonel (Dr.) Md. Mahabub, MBBS, FCPS (Surgery), OJT Colorectal Surgery (India). Classified Specialist in Surgery. Combined Military Hospital (CMH), Dhaka Cantonment.

b. Major General (Dr). Md. Mahbubur Rahman, MBBS, FCPS (Surgery), Fellow Colorectal Surgery (France). Consultant Surgeon General of Bangladesh Armed forces.

c. Colonel(Dr.) Md. Tanvirul Islam, MBBS, FCPS (Surgery), Fellow Colorectal Surgery (Singapore), Classified Surgical Specialist. Combined Military Hospital (CMH), Dhaka Cantonment.

d. Lt. Colonel (Dr.) Selina Sultana, MBBS, DGO, MCPS, FCPS (Gynae \& Obs). Classified Specialist in Gynae \& Obs. Combined Military Hospital (CMH), Dhaka Cantonment.

Address of correspondence: Lt. Colonel (Dr.) Md. Mahabub, MBBS, FCPS (Surgery), OJT Colorectal Surgery (India). Classified Specialist in Surgery. Combined Military Hospital (CMH), Dhaka Cantonment. Email: mraj712014@yahoo.com

Received: May 15, 2018

Accepted: July 31, 2018

\section{Introduction}

An anal fissure (synonym: fissure-in-ano) is a longitudinal split in the anoderm of the distal anal canal which extends from the anal verge proximally towards, but not beyond, the dentate line. ${ }^{1}$ Fissures are classified as acute or chronic, and chronic anal fissure (CAF) results from the progression of an acute anal fissure which has failed to heal over six weeks following its development. ${ }^{2,3}$ Anal fissure causes severe sharp pain on defecation, occasionally accompanied by streak of blood on outside of stool or blood on toilet tissue. Pain may persist for many hours after defecation that is much distressing to patients. ${ }^{4}$ According to Goligher's rule, the location of fissure is, almost $90 \%$ are posterior, around $10 \%$ are anterior and less than $1 \%$ occur 
simultaneously in the anterior and posterior positions. ${ }^{5}$ The CAF typically has inflamed and indurated margins with a base which has either scar tissue or the lower edge of the internal sphincter. ${ }^{3}$ A guarding sentinel pile is often found at its lower edge and a hypertrophied papilla proximally. ${ }^{3,4}$ When traction is applied on each side of the anus, the fissure appears to be triangular in shape, with the apex near the dentate line and the base over the lower anal canal. ${ }^{6}$ Fissures typically involve the internal anal sphincter and this goes into spasm and impedes healing by moving the two margins apart and diminishing the blood supply to the region. This, in addition to the exposure to fecal matter, accounts for the delays in the healing of fissures. ${ }^{7}$

Lateral internal sphincterotomy (LIS) remains the gold standard for definitive management of CAF, and can be performed by either an open [open lateral internal sphincterotomy (OLS)], or a closed [closed lateral internal sphincterotomy (CLS)] technique. ${ }^{8,9}$ Anal sphincter division was originally described to the dentate line, but recent reports describe a more conservative approach, either with division of the muscle to the fissure apex or with division just until the band of hypertrophied muscle is released. ${ }^{2}$ This procedure was originally described by Eisenhammer in 1951 as a midline posterior incision through the fissure. However, subsequent studies noted problems with wound healing and the formation of a "keyhole" deformity to the anus. ${ }^{10}$ The open technique was also used by Parks with a "circumferential incision" along the anal verge in the intersphincteric groove, but Ray et al. used a "radial incision" during LIS. ${ }^{9}$ Notaras reported a technique using a narrow-bladed scalpel to perform an internal anal sphincterotomy in a closed fashion in the lateral position. ${ }^{11}$ There have been many studies comparing the open and closed techniques. Some authors reported that LIS performed by the closed technique had lower complication rates than that by the open technique, but others reported that both of the techniques had no meaningful differences in complications. Therefore, until now, no definitive guidelines have been shown on the choice of the open or closed technique for performing LIS. ${ }^{9}$ The purpose of this study was to compare the results of the open and closed techniques of lateral internal sphincterotomy in terms of their postoperative outcomes.

\section{Methods}

This was a comparative and cohort study carried out at the Department of Colorectal Surgery, CMH Dhaka, Bangladesh, from October 2013 to October 2017. Eighty three (83) patients with CAF not responding to medical treatment for at least three months were included in this study to compare the results of the open versus closed techniques of LIS. Patients were divided into two groups in view of the distribution of age, sex and symptoms, physical examinations including the location of the fissure(s). Total 83 patients, out of which 42 (50.6\%) (23 male, 19 female) underwent OLS, and 41 (49.4\%) (23 male, 18 female) underwent CLS. In the anus the posterior midline fissure was seen in 40 (95.23\%) and 37 (90.24\%) patients, anterior midline fissure was $2(4.76 \%)$ and $3(7.31 \%)$ in OLS and CLS group respectively, and both anterior and posterior midline fissure was noted in $1(2.43 \%)$ patient of CLS group but no patient in OLS group (Table II). Patients with non-midline anal fissure, suggestive of anal manifestation of a systemic disease, were excluded from this study. Patients were operated under spinal (caudal) anesthesia in lithotomy position, by a colorectal surgeon or by a general surgery resident under guidance of a colorectal surgeon.

The OLS was done through a radial $1 \mathrm{~cm}$ incision overlying the intersphincteric groove of the perianal skin at 3 o'clock position. A delicate dissection was done in the intersphinc-teric plane and dissecting the internal anal sphincter away from the anoderm. The white hypertrophied band of internal sphincter muscle was then elevated into the wound with a curved hemostat. The lower one-third or one-half was divided with electro-cautery, then pressure was maintained for a few minutes to ensure good hemostasis. A CLS was done by insertion of a narrow anal retractor (e.g, HillFerguson) or index and middle finger of left hand, the tight distal internal anal sphincter is palpable as a tight band within the anal canal. A narrow blade scalpel (number 11) is introduced through the intersphincteric groove of perianal skin at the left lateral aspect of the anal canal at 3 o'clock position. The anal canal sandwiched parallel between the anoderm and the internal sphincter, when the tip of the blade reaches the dentate line, is turned in-ward and forward, and the internal sphincter muscle is divided with the blade controlled by the left index finger; about one third or 
one half of the sphincter was divided ${ }^{11,12}$, again the pressure is maintained for a few minutes to ensure good hemostasis. The sphincterotomy was checked by palpating the gap when the internal muscle fibers have been divided. ${ }^{13}$ All wounds were left open and healed through secondary intention. Gauze soaked with povidone Iodine solution was placed over the operated wound and a perianal pad was applied, which was removed 24 hours after surgery or when patient desires to pass stool. In the first postoperative day, local examination of the wound for any heamatoma, bleeding, bruises/ecchymosis was done. If there was no findings most of the patients were discharged within 48 hours after surgery and advised warm sitz bath, analgesics, and stool bulking agent for two to three weeks. A followup of four months was done by frequent visits on a predetermined basis and a telephone inquiry to document relief of defecatory anal pain, per-rectal bleeding, constipation, incontinence of flatus/faeces, wound infection and fissure recurrence. All the data were recorded on pre-structured data sheet. SPSS-20.0 was used for analysis.

\section{Results}

There were 83 patients (46 male and 37 female with male to female ratio $1.24: 1$ ) with CAF were studied. Majority of the patients were in between 22 years to 52 years and the mean age was $34.15 \pm 11.4$ years (Table I). Out of 83 patients, 42 (23 male, 19 female) underwent OLS, and 41 (23 male, 18 female) underwent CLS (Table I). Per-operative bleeding was seen in 15 (35.71\%) patients in the OLS group and $5(12.19 \%)$ in

the CLS group $(\mathrm{P}<0.05)$ (Table III). During postoperative period there was oozing from the operated wound in 2 patients in OLS group and there was no bleeding in CLS group. Oozing stopped spontaneously, but required changing of perineal pad postoperatively that was applied during operation as dressing. Urinary retention occurred in $2(4.76 \%)$ patients in

Table I Patient demography

\begin{tabular}{|c|c|c|}
\hline & $O L S n=42$ & $C L S n=41$ \\
\hline Average age (Years) & 35.2 & 33.1 \\
\hline \multicolumn{3}{|l|}{ Sex } \\
\hline Male & $23(50 \%)$ & $23(50 \%)$ \\
\hline Female & $19(51.35 \%)$ & $18(48.64 \%)$ \\
\hline
\end{tabular}

Table II Indications for Surgery of Chronic Anal Fissure (CAF)

$\operatorname{OLS}(\%) \mathrm{N}=42 \operatorname{CLS}(\%) \mathrm{N}=41$

Symptoms:

$\begin{array}{lcc}\text { Anal pain } & 42(100 \%) & 41(100 \%) \\ \text { Per-rectal bleeding } & 26(61.94 \%) & 15(36.58 \%) \\ \text { Constipation } & 25(59.52 \%) & 17(41.41 \%) \\ \begin{array}{l}\text { gns: Midline anal } \\ \text { ceration }\end{array} & 42(100 \%) & 41(100 \%) \\ \begin{array}{l}\text { Posterior midline } \\ \text { Anterior midline }\end{array} & 40(95.23 \%) & 37(90.24 \%) \\ \begin{array}{l}\text { Anterior and posterior } \\ \text { midline }\end{array} & 3(7.31 \%) \\ \end{array}$

Table III Comparison of outcome between OLS and CLS

\begin{tabular}{lcccc}
\hline Complication & \multicolumn{3}{c}{ Operation } & \\
\cline { 2 - 4 } & OLS n=42 & CLS n=41 & Relative Risk & p-Value \\
\hline Per-operative bleeding & $15(35.71 \%)$ & $5(12.19 \%)$ & $0.34(0.14-0.85)$ & 0.022 \\
Urinary retention & $2(4.76 \%)$ & - & $0.21(0.01-4.34)$ & 0.315 \\
Symptom relief & $32(76.19 \%)$ & $29(70.73 \%)$ & $1.23(0.60-2.52)$ & 0.574 \\
Pain after 1s POD & $14(33.33 \%)$ & $3(7.31 \%)$ & $0.22(0.07-0.71)$ & 0.011 \\
Faecal soiling & $1(2.38 \%)$ & - & $0.34(0.01-8.14)$ & 0.507 \\
Flatus incontinence & $3(7.14 \%)$ & - & $0.15(0.01-2.79)$ & 0.200 \\
Wound Infection & - & - & - & - \\
Fissure recurrence & - & $6(14.63 \%)$ & $13.3(0.77-228.92)$ & 0.074 \\
\hline
\end{tabular}

* The Relative Risk (RR), its standard error and 95\% confidence interval are calculated according to Altman 1991. 
OLS vs no patient in CLS group ( $\mathrm{p}=0.315$ ) (Table III), which was transient and improved after warm sitz bath, all were male and age was $>45$ year. Patients who underwent OLS, 32 (76.19\%) were free of symptoms (anal pain, per rectal bleeding and constipation) on the $1^{\text {st }}$ post-operative day, and, in patients who underwent CLS, $29(70.73 \%)$ were free of symptoms ( $p=0.574)$ (Table III). In OLS group 14 (33.33\%) patients had significant $1^{\text {st }}$ post-operative day pain in the operated wound but only $3(7.31 \%)$ patients had it in CLS group, which is statistically significant $(\mathrm{p}=0.011)$ (Table III). After one week $6(14.28 \%)$ patients complained of pain in OLS group compared to $1(2.43 \%)$ patient in CLS group, the pain improved within two weeks postoperatively. Soiling of underclothes occurred in 1 $(2.38 \%)$ patient in OLS group and no patient in CLS group ( $\mathrm{p}=0.507$ ) (Table III), which was temporary and last up to two months. Mild incontinence to flatus, which was temporary, was found in $3(7.14 \%)$ patients in OLS group compared with no patients in CLS group $(p=0.200$ (Table III); all recovered by conservative management including perineal exercises within two months of surgery. No patient in either group suffered from perianal infections (Table III). There were $6(14.63 \%)$ patients with anal fissure recurrence, with in four month of surgery in CLS group, but none in OLS group $(p=0.74)$ (Table III), in 3 patients fissure was healed conservatively within four months during follow up, and in other 3 patients OLS was done, after which fissure was healed. In the OLS group 41 (91.93\%) patients, and on the other hand 37 (72.41\%) patient in CLS group described their operation as satisfactory. Regarding postoperative complications like pain, bleeding and incontinence, all were less in the CLS group, but fissure recurrence was higher.

\section{Discussion}

There are many modalities of treatment of chronic anal fissure, but lateral internal sphincterotomy (LIS) has been regarded as the gold standard which is performed in both open (OLS) and closed (CLS) technique. ${ }^{7}$ In this study all OLS and CLS were performed under spinal (caudal) anesthesia. Most of the published studies have used either spinal or general anesthesia.

In this study per-operative bleeding was seen in $35.71 \%$ patients in the OLS group and $12.19 \%$ patients in the CLS group. When the results of open and closed techniques were compared with other studies, per- operative bleeding were reported by Mousavi Jr RS $(67.5 \% \text { vs } 38 \%)^{14}$, Anandaravi BN et al $(16 \% \text { vs } 4 \%)^{15}$ respectively. During Postoperative period bleeding were reported by Kata AA et al ( $8 \%$ vs $4 \%)^{12}$, Sarhan $\mathrm{HH}$ $(4 \% \text { vs } 0 \%)^{13}$, and Sanniyasi S et al $(5 \% \text { vs } 0 \%)^{16}$. CLS method causes less bleeding than OLS due to less tissue damage during operation.

Urinary retention occurred in $4.76 \%$ patients in OLS group, but no patient in CLS group, which was transient and improved after warm sitz bath. In the study of Gautam MR, urinary retention occurred in $11.5 \%$ in OLS vs $0 \%$ in CLS group. ${ }^{17}$

In this study $76.19 \%$ patients in OLS group and $70.73 \%$ patients in CLS group were free of symptoms (defecatory anal pain, per rectal bleeding and constipation) on the $1^{\text {st }}$ post-operative day, which is comparable to Sarhan $\mathrm{HH}(80 \% \text { vs } 92 \%)^{13}$, Anandaravi BN et al (42\% vs $82 \%)^{15}$, and Sanabani AJ et al $(71.4 \%$ vs $80 \%)^{18}$ respectively. Postoperative endoanal ultrasounds showed that open sphincterotomy was associated with a significantly higher proportion of complete sphincterotomies $^{2}$, so in present study early relief of symptoms were seen more in the OLS group.

This study also reflects that $33.33 \%$ patients in OLS group and $7.31 \%$ patients in CLS group had significant 1 st post-operative day pain in the operated wound which improved within two weeks postoperatively. Mousavi Jr RS reported that in the first postoperative day $45 \%$ of the study group (CLS) complained of pain, compared to $76 \%$ of the control group (OLS). ${ }^{14}$ Gautam MR reported, in open sphincterotomy patients there was significant pain for 5 days and in closed sphincterotomy patients there was significant pain for 2 days. ${ }^{17}$ Because of more tissue dissection during open technique of LIS causes more pain.

Fecal incontinence occurred in no patient in the CLS group and in only one patient in the OLS group which was temporary and improved within two months. This finding is almost similar to that of Kataa AA et al. ${ }^{12}$ and better than Gautam MR ${ }^{17}$ who reported soiling of underclothes in $26.7 \%$ patients in open sphincterotomy group and $16.1 \%$ in closed sphincterotomy group. Mild incontinence to flatus, which was temporary, was found in $7.14 \%$ patients in OLS group compared with no patients in CLS group, all recovered by conservative management including perineal exercises within two 
months of surgery. This result is better than all other previous studies. ${ }^{12,13,17}$

No patient in either group suffered from perianal infections in this study. This finding is similar to Gautam $\mathrm{MR}^{17}$ and better than Kataa AA et al. $(6 \% \text { vs } 6 \%)^{12}$, and Sanniyasi S et al. (3\% vs 0$)^{16}$.

There was no anal fissure recurrence within 4 months in OLS group and only $14.63 \%$ recurrence in the CLS group in this study. Among them half of the patients' fissure was healed conservatively within four months, and other half OLS was done, after that fissure was healed. Kataa AA et al reported ( $8 \%$ vs $8 \%)^{12}$, Gautam MR reported (3.1\% vs 5.9\%) ${ }^{17}$ and Sanabani AJ et al. reported ( $2 \%$ vs $6 \%)^{18}$ anal fissure recurrence in open versus closed technique.

In this study $91.9 \%$ patients in the OLS group and $72.4 \%$ patients in the CLS group described their operation as satisfactory. This finding is similar to Gautam $\mathrm{MR}^{17}$ who reported $90 \%$ of overall patient satisfaction.

This study had some limitations. It is a single cantered study. The patients were followed for four months only, owing to which recurrence beyond that time limit could not be assessed.

\section{Conclusion}

The lateral internal sphincterotomy performed by the closed technique had lower post-operative complications, pain, bleeding, and incontinence compared to open technique, but increased risk of incomplete division of the internal sphincter may cause fissure recurrence. So, given the lower rate of recurrence and greater symptomatic relief and satisfaction of patients, open technique could be considered as perhaps preferable approach in the surgical management of chronic anal fissures, especially for the beginner's and the closed technique should be adopted by more experienced surgeons.

Conflict of interest: Nothing to declare.

\section{References}

1. Williams SN, Bulstrode JKC, O'Connell RP. Bailey \& Love's Short Practice of Surgery. $26^{\text {th }}$ ed. London: Taylor and Francis Group; 2013. p. 1248-50.

2. Kim C, Lu and Daniel O, Herzin. Anal fissure. In: Steele RS, Hull LT, Read ET, Saclarides JT, Senagore JA, Whitlow BC, editors. The ASCRS Textbook of Colon and Rectal Surgery. $3^{\text {rd }}$ ed. New York: Springer International Publishing; 2016. p. 205-210.
3. Zubair M, Saaiq M, Shah AS. Efficacy and safety of subcutaneous lateral internal sphincterotomy for chronic anal fissure. J Ayub Med Coll Abbottabad 2014; 26(2): 141-44.

4. Shaikh RA, Rao KMA, Muneer A. A comparative study of the results of the anal fissurectomy and lateral internal sphincterotomy for chronic anal fissure. Pak J Med Sci 2012; 28(1): 112-15.

5. Welton LM. Anorectum. In: Way WL, Doherty MG, editors. Current Surgical Diagnosis and Treatment. $11^{\text {th }}$ ed. New York: McGraw-Hill Companies; 2005. p. 769-70.

6. Mohan NPS, Chandrasekar R, Chetty V. Comparative study of manual anal dilatation with fissurectomy versus lateral anal sphincterotomy in chronic fissure in ano. MedPulseInternational Medical Journal 2016; 3(2): 167-70.

7. Gupta V, Rodrigues G, Prabhu R, Ravi C. Open versus closed lateral internal anal sphincterotomy in the management of chronic anal fissures: A prospective randomized study. Asian Journal of Surgery 2014; 37: 178-83.

8. Patel HS, Chavda J, Parikh J, Naik N. Study of Operated Patients of Lateral Internal Anal Sphincterotomy for Chronic Anal Fissure. J Clinic Diagn R 2013; 7(12): 2863-65.

9. Kang HW, Lim HC, Choi HD, Shin KH, Lee CY, Jeong KS et al. Comparison of skin incisions used for open lateral internal sphincterotomies - Radial versus circumferential incisions: A retrospective cohort study. Inter J Surg 2014; 5: 1141-45.

10. Simmang LC, Papaconstantinou TH, Huber JP Jr. Fissure-inAno. Yeo JC, editor. Shackelford's surgery of the alimentary tract. $7^{\text {th }}$ ed. Philadelphia, Pennsylvania: Elsevier Inc; 2013. p. 1907-13.

11. Jobanputra PS. Anal fissure. In: Corman LM, editor. Corman's colon and rectal surgery. $6^{\text {th }}$ ed. Philadelphia: Lippincott Williams \& Wilkins; 2013. p. 346-66.

12. Kataa AA, Al-Hawaz HM. Closed versus open lateral internal sphincterotomy in treatment of chronic anal fissure; a comparative study of postoperative complications \& outcome. Bas J Surg 2010; 16: 10.

13. Sarhan HH. Closed Versus Open Lateral Internal Sphincterotomy in Treatment of Chronic Anal Fissure: A Comparative Study. Arch Clin Exp Surg 2012; 1: 219-23.

14. Mousavi Jr RS. Closed Versus Open Lateral Internal Sphincterotomy Technique in Treatment of Anal Fissure. World J Colorectal Surg 2013; 3(3): 5.

15. Anandaravi BN, Ramaswami B. Closed versus open lateral internal anal sphincterotomy in a chronic anal fissure. Int Surg J 2017; 4(3): 1055-1058.

16. Sanniyasi S, Alexander N, Thiyagarajan M. Open Versus Closed Lateral Internal Sphincterotomy in Chronic Anal Fissures: A Prospective Study. Inter J Scient Study 2016; 4(7).

17. Gautam MR. Open versus Closed Lateral Internal Anal Sphincterotomy for the Treatment of Fissure in ANO - A Rural Indian Experience. JIMSA 2013; 26(3): 177.

18. Sanabani AJ, Salami AS, Saadi AA. Closed versus open lateral internal anal sphincterotomy for chronic anal fissure in female patients. Egypt J Surg 2014; 33: 178-81. 